\title{
FORMAÇÃO DOS EGRESSOS DO CURSO TÉCNICO EM ADMINISTRAÇÃO DO IFNMG - CAMPUS ARINOS ${ }^{1}$
}

\author{
Training of technical course in Administration of IFNMG - Campus Arinos \\ MOTA, Valdinice ${ }^{2}$ \\ BRAGA, Denise ${ }^{3}$
}

\begin{abstract}
Resumo
Este artigo analisa como o Curso Técnico em Administração do IFNMG - Campus Arinos repercute na inserção social e profissional no Vale do Urucuia, a partir da visão dos egressos. Buscamos estudar o envolvimento dos alunos com as disciplinas ofertadas, seus interesses, realidades, dificuldades e o incômodo: qual o papel do Campus Arinos na formação destas pessoas? O Curso Técnico em Administração contribui para a inserção social e profissional dos alunos? Para este estudo foi feita a coleta primária de dois conjuntos de informações e dados, simultaneamente, sendo utilizada abordagem quantiqualitativa. A pesquisa de enfoque quantitativo com os egressos foi realizada mediante aplicação de questionário on-line com perguntas fechadas. Foram obtidos 118 conjuntos de respostas dos egressos de 161 questionários disponibilizados e realizadas 7 entrevistas, com um egresso de cada turma. A pesquisa revela forte aceitação do curso por parte dos alunos, no entanto, ressalta também limitações que afetam o desenvolvimento do egresso em relação à sua inserção profissional. Esperamos ter sinalizado pontos merecedores de reflexões por parte dos gestores da educação pública no Brasil.
\end{abstract}

Palavras-chave: Ensino Técnico. Pesquisa com egressos. Educação profissional.

\begin{abstract}
This article analyzes how the Technical Course in Administration at IFNMG - Campus Arinos has repercussions on social and professional insertion in the Urucuia Valley, from the perspective of the graduates. We seek to study the involvement of students with the subjects offered, their interests, realities, difficulties and discomfort: what is the role of Campus Arinos in the training of these people? Does the Technical Course in Administration contribute to the social and professional insertion of students? For this study, the primary collection of two sets of information and data was made simultaneously, using a quantitative-qualitative approach. The research with a quantitative focus with the alumni was carried out by applying an online questionnaire with closed questions. 118 sets of responses were obtained from the graduates of 161 questionnaires made available and 7 interviews were conducted, with one graduate from each class. The research reveals strong acceptance of the course by the students, however, it also highlights limitations that affect the development of the graduate in relation to his professional insertion. We hope to have signaled points worthy of reflection on the part of public education managers in Brazil.
\end{abstract}

Keywords: Technical education. Search with graduates. Professional education.

\footnotetext{
${ }^{1}$ O texto passou pela avaliação de Comitê de Ética em Pesquisa (CEP/UFVJM), tem financiamento Do IFNMG; é resultante de pesquisa de dissertação do Mestrado em Educação da UFVJM.

${ }^{2}$ Mestre em Educação pela Universidade Federal dos Vales do Jequitinhonha e Mucuri - UFVJM, Graduação em Administração pela Universidade Estadual de Montes Claros - UNIMONTES. Professora de Ensino Básico e Tecnológico do Instituto Federal do Norte de Minas Gerais - IFNMG. Coordenadora do curso de Bacharelado em Administração - IFNMG - Campus Arinos. E-mail: valdinice.mota@ifnmg.edu.br

${ }^{3}$ Doutora em Educação pela Universidade do Estado do Rio de Janeiro - UERJ, Mestre em Educação pela Pontifícia Universidade Católica de Minas Gerais, Graduação em Pedagogia pela Universidade do Estado de Minas Gerais. Professora Adjunta da Universidade Federal dos Vales do Jequitinhonha e Mucuri - UFVJM. Coordenadora do curso de Licenciatura e Pedagogia - UFVJM. Docente do Programa de Pós-Graduação-Mestrado em Educação. E-mail: denise.braga@ưvjum.edu.br.
} 


\section{INTRODUÇÃO}

Na primeira década do século XXI, no Brasil, no período de 2003 a 2016, a educação profissional da Rede Federal de Ensino vivenciou a maior expansão de sua história. Segundo o Portal do Ministério da Educação e Cultura - MEC (2004), foram construídas mais de 500 novas unidades referentes ao plano de expansão da educação profissional, totalizando 644 campi em funcionamento. Atualmente, são 38 Institutos Federais presentes em todos os estados, que oferecem cursos de qualificação para todas as pessoas que tenham interesse nas conquistas científicas e tecnológicas, no Ensino Médio Integrado, aos cursos superiores de tecnologia e licenciaturas.

Esta pesquisa buscou responder especificamente a seguinte pergunta: de que forma o Curso Técnico em Administração do IFNMG - Campus Arinos repercute na inserção social e profissional no Vale do Urucuia, a partir da visão dos egressos? Assim, o objetivo geral deste trabalho consiste em analisar a prática social dos egressos, sua inserção no mundo do trabalho e seu efeito em termos de melhoria da renda e qualidade de vida, com os seguintes objetivos específicos: identificar a inserção social e profissional dos egressos do Curso Técnico em Administração no período de 2011 a 2017 no Vale do Urucuia; analisar a correlação existente entre a formação obtida no Curso Técnico em Administração e possíveis transformações sociais e profissionais na vida dos egressos; levantar dados que auxiliem na implementação de políticas de acompanhamento de egressos no IFNMG - Campus Arinos.

A justificativa para o presente trabalho é que, na região do Vale do Urucuia, não são correntes as ações de realizar análises de impacto em programas de qualificação profissional. Apontamos ainda- o acompanhamento de transformações, na perspectiva de uma avaliação contínua da formação ofertada no IFNMG - Campus Arinos, dos seus currículos, do perfil profissional dos egressos e a necessidade de uma formação profissional continuada.

O Curso Técnico em Administração no IFNMG - Campus Arinos tem a duração de 3 Módulos/semestrais. O ingresso no curso acontece por meio de inscrição em processo seletivo com entrada anual. Podem ser admitidos no curso alunos que estejam cursando a 2 ${ }^{-}$ou a $3^{\underline{a}}$ séries do ensino médio ou que já tenham concluído o Ensino Médio (IFNMG, 2017). Foi criado a partir do projeto de expansão da Rede Federal de Ensino e atendeu aos anseios da comunidade, por meio de audiência pública ocorrida na cidade, ainda em 2008, na definição dos cursos para serem ofertados pela Instituição, conforme previsto no PDI 2014 - 2018.

Atualmente, os Cursos de nível técnico do Campus Arinos visam atender às deficiências de tecnologias e mão de obra qualificada na região, e buscam formas de reverter 0 êxodo, assegurar condições de renda e sustentabilidade nas suas respectivas regiões (BRASIL, 2017). Sendo assim, a pesquisa é importante para o IFNMG e a sociedade, pois apresenta informações sobre a formação dos egressos e sua relação com a inserção profissional, evidenciando os impactos da formação dos egressos no desenvolvimento social e econômico da região.

$\mathrm{Na}$ estrutura deste artigo, abordaremos a história da educação profissional no Brasil, contextualizaremos o Instituto Federal do Norte de Minas Gerais - Campus Arinos, bem como a origem, os desdobramentos e a legislação que instituiu o IFNMG - Campus Arinos. Apresentaremos o tipo e abordagem da pesquisa, os instrumentos e as técnicas 
de coleta e análise dos dados, bem como relataremos quem foram os sujeitos da pesquisa. E, ao final, abordaremos os resultados e discussões.

Nas considerações finais, momento em que, com base na análise da pesquisa, identificaremos e passaremos a compreender com maior clareza a inserção profissional e social dos egressos do Curso Técnico em Administração do IFNMG - Campus Arinos. Assim, esperamos que a pesquisa contribua com os estudos sobre a inserção do egresso dos cursos técnicos profissionalizantes no mundo do trabalho, sem que com isso eles deixem de dar continuidade aos estudos em nível superior.

\section{EDUCAÇÃO PROFISSIONAL NO BRASIL}

A educação profissional, em sua relação com o trabalho, historicamente esteve relacionada à formação de mão de obra, e foi utilizada para tal finalidade a educação de jovens e adultos das classes menos favorecidas. No curso da história, a aprendizagem foi direcionada ao desenvolvimento de habilidades manuais, ficando o conhecimento das disciplinas propedêuticas em um plano secundário, havendo claramente uma separação de classes: os que pensam e os que executam. Para Frigoto, Ciavatta e Ramos,

Como formação humana, o que se busca e garantir ao adolescente, ao jovem e ao adulto trabalhador o direito a uma formação completa para a leitura do mundo e para a atuação como cidadão pertencente a um país, integrado dignamente a sua sociedade política. Formação que, neste sentido, supõe a compreensão das relações sociais subjacentes a todos os fenômenos (FRIGOTTO; CIAVATTA; RAMOS, 2005, p. 85).

Moura (2007) também chama a atenção para isso, ao afirmar que a educação até o século XIX reforçava a reprodução das classes sociais. A educação propedêutica com ênfase nas ciências, letras e artes era destinada aos filhos das classes altas e buscava, com isso, formar os futuros dirigentes, ao passo que, para as demais classes, o acesso aos conhecimentos citados foi negado. Assim, por consequência uma relação da educação marcada pela dualidade estrutural do ensino, visando, para as classes populares, a formação da massa de trabalhadores.

Durante o governo Vargas, acabou a vinculação dos recursos para a educação e as escolas vocacionais e pré-vocacionais foram criadas. Segundo Moura (2007), as "escolas vocacionais e pré-vocacionais" deveriam preparar os filhos dos operários com a colaboração dos sindicatos e das indústrias.

Após a Reforma Capanema em 1942, a educação brasileira ficou estruturada em dois níveis: básico e superior. Essa reforma estabeleceu um sistema paralelo de educação, acentuando a velha tradição, o ensino propedêutico e o ensino profissional, instituiu cursos profissionalizantes e formalizou a dualidade do ensino no Brasil. "Consolidou-se assim a dualidade dentro do sistema público de Ensino, levada às últimas consequências na dualidade de sistemas, resultado final da gestão Capanema no que tange ao ensino técnico-profissional" (XAVIER, 1990, p. 114).

Com a publicação da primeira Lei de Diretrizes e Bases da Educação Nacional (LDBEN), Lei 4.024, em 20 de dezembro de 1961, os egressos do ensino técnico puderam candidatar-se a cursos superiores (BRASIL, 1961). Ao mesmo tempo em que a legislação amparava os egressos dos cursos técnicos a ingressarem nos cursos superiores, intensificava a necessidade de oferta de educação profissional, reforçando o discurso de qualificação para atender o processo produtivo. 
Em 1971, sob o regime ditatorial, aconteceu uma profunda reforma da educação básica promovida pela Lei no 5.692/71, visando estruturar o nível médio como sendo profissionalizante para todos. Assim, o governo autoritário, como opção política sustentada em um modelo de desenvolvimento econômico por ele potencializado, decidiu dar uma resposta às classes populares: a utilização da formação técnica profissionalizante, em nível de $2^{\circ}$ grau, para garantir a inserção no mercado de trabalho (MOURA, 2007).

Analisando a reforma que tornou a educação profissional compulsória na Lei oㅜ 5.692/1971 (BRASIL, 1971), visto a obrigatoriedade dos cursos técnicos no $2^{\circ}$ grau, com disciplinas da área propedêutica e técnicas, todas as pessoas teriam acesso à mesma formação. Mas, segundo Moura (2007), a realidade foi diferente, pois, na prática, a obrigatoriedade foi somente na educação pública e as escolas privadas continuaram com os currículos propedêuticos, formando para acesso à Educação Superior, atendendo às classes com condições financeiras para pagar pelo ensino.

[...] a velha dualidade ressurgiu no âmbito da legislação com todo o seu vigor, reafirmandose novamente na oferta propedêutica, como a via preferencial para ingresso no nível superior, permanecendo os velhos ramos como vias preferenciais de acesso ao mundo de trabalho (KUENZER, 1997, p. 24).

A educação profissional nos sistemas públicos estaduais ocorreu em áreas em que não havia demandas por uma infraestrutura específica e especializada, proliferando cursos que, rapidamente, foram saturados de profissionais no mundo do trabalho, banalizados de formação e desprestígio, por falta de financiamentos e de formação de professores (MOURA, 2007).

$\mathrm{Na}$ esfera federal, a atuação das Escolas Técnicas Federais foi diferente dos demais sistemas públicos, porque contou com financiamento adequado, corpo docente especializado e com política de remuneração muito diferente. Assim, as Escolas Técnicas Federais, consolidaram-se como referência de qualidade na formação de técnicos de nível médio, sendo importante ressaltar que elas não mantiveram seus currículos nos limites restritos de instrumentalidade para o mundo do trabalho, estabelecidos pela Lei no 5.691/1971 (MOURA, 2007).

Com a Lei no 8.948, de 8 de dezembro de 1994 (BRASIL, 1994), o Governo Federal trata da instituição do Sistema Nacional de Educação Tecnológica, transformando, gradualmente, as Escolas Técnicas Federais e as Escolas Agrotécnicas Federais em Centro Federal de Educação Tecnológica (CEFET), mediante decreto próprio para cada instituição e em função de critérios que foram estabelecidos pelo Ministério da Educação. Para tanto, levou em consideração as instalações físicas, os laboratórios e equipamentos adequados, as condições técnico-pedagógicas e administrativas, e os recursos humanos e financeiros necessários à atividade de cada centro.

Em meio a transformações difíceis e polêmicas da educação profissional de nosso país, retoma-se, em 1999 com o Parecer CNE/CEB no 16/99 (BRASIL, 1999), o processo de modificação das Escolas Técnicas Federais em Centros Federais de Educação Tecnológica, iniciado em 1978.

Assim, foram construídas 140 unidades de ensino, de 1909 a 2002, na Rede Federal de Educação Profissional e Tecnológica brasileira. O Decreto 5.154/2004 permitiu a integração do Ensino Técnico ao Ensino Médio, articulou as disciplinas propedêuticas com as disciplinas técnicas de forma integrada e com ampliação da carga horária total 
do curso, de acordo com as Diretrizes Curriculares Nacionais (DCNs). Em 2005, com a publicação da Lei 11.195, que trata da expansão da oferta de educação profissional, mediante a criação de novas unidades de ensino por parte da União, ocorre o lançamento da primeira fase do Plano de Expansão da Rede Federal de Educação Profissional e Tecnológica, com a construção de 64 novas unidades de ensino (BRASIL, 2017).

A Rede Federal de Educação Profissional e Tecnológica brasileira vivenciou a maior expansão de sua história entre 2003 e 2016, segundo o Portal do Ministério da Educação e Cultura - MEC (BRASIL, 2017).

A Rede Federal de Educação Profissional e Tecnológica está alicerçada em uma história de implantação de 100 anos, cujas atividades iniciais eram instrumento de uma política voltada para os "desafortunados" e, hoje, cobrindo todo o território nacional, presta um serviço à nação, dando continuidade à sua missão de qualificar profissionais para os setores diversos da economia do Brasil e configura-se como uma relevante organização para que todas as pessoas tenham acesso às conquistas científicas e tecnológicas (BRASIL, 2017).

\section{A EDUCAÇÃO PÚBLICA A PARTIR DO IFNMG - CAMPUS ARINOS}

O IFNMG foi criado em 29 de dezembro de 2008, pela Lei ํㅜ 11.892, mediante integração do Centro Federal de Educação Tecnológica de Januária e da Escola Agrotécnica Federal de Salinas, instituições com mais de 50 anos de experiência na oferta da educação profissional. Atualmente, agrega outros sete Campi (Almenara, Araçuaí, Arinos, Pirapora, Montes Claros, Diamantina, Teófilo Otoni) e a Unidade de Educação Profissional - Campus Avançado de Janaúba e Porteirinha, vinculadas ao IFNMG - Campus Montes Claros (BRASIL, 2013).

O município de Arinos teve, no ano de 2009, a instalação do IFNMG. Após ser escolhido como sede, a instituição contou com o apoio de diferentes parceiros. O IFNMG Campus Arinos está situado em área rural a aproximadamente 5,0km do centro municipal, possui área própria de $579.000 \mathrm{~m}^{2}$ devidamente escriturada e registrada no Cartório de Registro de Imóveis de Arinos, toda em nome do IFNMG - Campus Arinos.

Dentro de uma perspectiva microeconômica de crescimento da economia da região, a política de educação profissional e tecnológica do IFNMG - Campus Arinos assume cada vez mais importância, sendo a única instituição de ensino público que oferece a educação profissional e tecnológica na região, pois constitui "elemento estratégico para a construção da cidadania e para melhor inserção de jovens e trabalhadores na sociedade contemporânea, plena de grandes transformações e marcadamente tecnológica" (MEC, 2004, p. 7).

Assim, constitui um grande desafio para o IFNMG - Campus Arinos implementar as políticas de educação profissional e tecnológica em função de problemas econômicos, estruturais, sociais e culturais da região do Vale do Urucuia, pois, segundo o Programa das Nações Unidas para o Desenvolvimento (BRASIL, 2013), a cidade situa-se em uma região com vulnerabilidade social significativa com o Índice de Desenvolvimento Humano Municipal (IDHM) de 0,656 em 2013. Em relação aos 853 municípios de Minas Gerais, Arinos ocupa a 592ª posição, sendo que 591 (69,28\%) municípios estão com o IDHM (longevidade, educação e renda) melhor e 262 (30,72\%) municípios estão em situação pior ou igual. 
Considerar a multiplicidade dos papéis das organizações torna-se fundamental não apenas políticas públicas que tenham impacto na realidade social da região, mas uma política educacional que possa potencializar o aproveitamento de oportunidades, com vistas à formação de determinada cidadania (NEVES, 2000), compreender, sobretudo, o trabalho como um princípio educativo, com significado econômico, social, histórico, político e cultural da sua formação. O IFNMG buscou expressar, através do seu PDI, no período 2014-2018, o compromisso com as demandas da sociedade.

\section{PROCEDIMENTOS METODOLÓGICOS}

A pesquisa se configura em uma abordagem quantiqualitativa e a coleta de dados de informações se efetivou por meio de análise documental das pastas dos alunos, questionário e entrevista com os egressos do curso. Os questionários foram aplicados aos egressos, disponibilizando link de acesso nos e-maile WhatsApp através do Google docs. O questionário é considerado como a forma mais comum de se coletar dados em uma pesquisa nas ciências humanas ou sociais (MALHEIROS, 2011, p.137).

Os sujeitos do estudo foram 161 egressos do Curso Técnico em Administração, do período entre 2011 e 2017, como resultado da consulta e levantamento de dados, realizados nas atas das formaturas, arquivadas na Secretaria do Ensino Médio do Campus Arinos. A pesquisa se iniciou por meio de contato com a Direção de Ensino do IFNMG - Campus Arinos para obtenção do TCLE, quando foi apresentada a proposta da pesquisa.

A partir da autorização assinada, iniciaram-se as consultas nos documentos de matrícula, arquivados na Secretaria do Ensino Médio do IFNMG - Campus Arinos. O objetivo foi relacionar os nomes, endereços e telefones dos egressos com a colaboração da Secretaria do Ensino Médio do IFNMG - Campus Arinos, para o posterior contato, por meio de ligações telefônicas, e-mail e grupos de egressos no WhatsApp.

Com as informações coletadas, foram aplicados os questionários para 154 egressos, e realizadas 7 entrevistas, com um egresso de cada turma. Ao final, foi realizada análise dos dados e apresentação dos resultados. A análise do questionário foi realizada por meio de técnicas de estatística básica no cálculo de percentual para as questões com uma opção para marcar, pois "percentual é uma medida que descreve quantas vezes uma ocorrência aparece a cada cem" (MALHEIROS, 2011, p.173) e para as questões por escala, analisadas através da escala de Likert, que busca desenvolver um conjunto de afirmações relacionadas a uma definição, para as quais os respondentes possam emitir seu grau de concordância (JÚNIOR E COSTA, 2014).

A análise das entrevistas e documentos foi por meio de análise do conteúdo, utilizando o método lógico-semântico com o qual "o pesquisador se debruçará sobre o conteúdo coletado, não importa a forma escolhida ou estética do discurso, o conteúdo passa a ser preponderante" (MALHEIROS, 2011, p. 207).

\section{A PERCEPÇÃO DOS EGRESSOS DO CURSO}

Os egressos do curso são predominantemente do sexo feminino (61\%). Por um lado, é sabido que não só é a população feminina que procura este tipo de ensino, tendo em vista uma necessidade de qualificação, mas, por outro lado, é essencial notar que a 
conclusão do curso por parte do sexo masculino (39\%) é muito reduzida em relação ao sexo feminino.

Os principais efeitos do Curso Técnico em Administração no desenvolvimento socioeconômico e/ou cultural na Região do Vale do Urucuia concentram-se na mão de obra qualificada para o mundo do trabalho, tanto para investir em negócio próprio quanto para trabalhar nas instituições públicas e privadas da região. Todos os entrevistados destacaram como benefício os conhecimentos adquiridos e consequentemente a qualificação na área.

Portanto, o Curso Técnico em Administração está condizente- em relação à formação oferecida para atender à necessidade local por qualificação profissional, na visão dos entrevistados, pois, segundo eles, os conhecimentos adquiridos proporcionaram a qualificação necessária para o mundo do trabalho. Quanto às ofertas na região de emprego na área técnica em Administração, 58\% responderam que há pouca oferta de emprego ou trabalho, $30 \%$ responderam que praticamente não há oferta de emprego para os profissionais da sua área técnica, $9 \%$ acreditam que há oferta de emprego ou trabalho, $2 \%$ não sabem e $1 \%$ há muitas ofertas de emprego ou trabalho para os profissionais da sua área técnica.

Os egressos do curso encontram dificuldades de inserção no mundo do trabalho na região e remuneração adequada. 39\% dos egressos recebem até 1 salário mínimo e $40 \%$ estão entre 1 e 2 salários mínimos. Na visão de $55 \%$ dos egressos, a remuneração em relação ao mercado está na média, mas $32 \%$ consideram que estão abaixo da média, $8 \%$ muito abaixo da média e somente $5 \%$ acima da média do mercado.

$\mathrm{Na}$ questão sobre vida profissional pregressa, buscamos analisar se houve transformação após a conclusão do curso. 52\% dos egressos já trabalhavam no mercado formal antes de iniciar o curso, $28 \%$ no mercado informal e, por fim, $20 \%$ não trabalhavam. Relacionando estes dados com a situação de empregabilidade atual, percebemos que o Curso Técnico em Administração possibilitou a redução do número de desempregados em $8 \%$.

Mesmo com a oferta dos cursos de graduação do Campus Arinos, 40\% dos egressos não continuaram os estudos. A fragilidade dos conteúdos adquiridos na vida escolar geralmente insuficientes contribuiu para a dificuldade no acesso às vagas oferecidas no ensino superior, pois, das 5 escolas estaduais da cidade de Arinos, somente 2 escolas estaduais apresentaram participação maior que $50 \%$ no Exame Nacional do Ensino Médio (Enem).

Dos 7 entrevistados, somente 2-acreditam que a mão de obra qualificada buscou se fixar na região, pois, segundo os egressos, a maioria dos colegas está trabalhando em outras regiões, principalmente em Brasília - DF. Analisando a percepção dos 7 entrevistados, percebemos, pelas respostas, que a formação obtida na instituição constitui uma solução para a evolução profissional.

Por outro lado, 4 entrevistados afirmam que, na realidade, existe escassez de oportunidade de emprego na região. Em outras palavras, consideram a região muito pobre, sendo que o mercado de trabalho ficou saturado com poucas turmas formadas. Contrapondo-se ao que preconiza o Projeto Pedagógico do Curso - PPC (IFNMG, 2017), pode-se observar que em geral não há qualquer garantia de que os egressos permaneçam em suas localidades de origem para atender o projeto do curso. 
De forma geral, a maioria dos egressos (52\%) nunca trabalhou na área técnica de formação, pois $85 \%$ dos egressos estão entre muito satisfeitos e satisfeitos com o curso. Nesse sentido, podemos concluir que a falta de oferta de empregos na região para área técnica de Administração justifica as respostas.

Uma das preocupações da educação profissional está relacionada ao aproveitamento da formação obtida, bem como se o diferencial da qualidade de ensino da instituição constituiu de fato um diferencial para a vida dos egressos. Buscamos avaliar esta questão por meio do questionamento em relação ao trabalho atual e à formação no Curso Técnico em Administração. 41\% dos egressos consideram que o trabalho está relacionado com área profissional do curso e 16\% consideram fortemente relacionada, $19 \%$ consideram fracamente relacionada, $17 \%$ consideram que não tem nenhuma relação com o curso, e 7\% não sabem informar.

Correlações negativas foram identificadas, entre o nível de aprendizagem durante 0 curso e atuação dos egressos na área de formação, pois $56 \%$ dos egressos não trabalham na área de atuação do Curso de Administração, sendo o motivo a falta de ofertas de trabalho na região. Então, observa-se que não existe uma fórmula para vincular a formação no curso com a absorção dos egressos pelo mundo do trabalho, sendo que este possui diversas variáveis sobre as quais a escola não possui controle, mas busca-se minimizá-las com ações para aproximar os alunos com o mundo do trabalho, por meio do estágio, projetos de extensão e eventos institucionais com a participação dos empresários da região.

A inserção no mundo do trabalho significa, nesta perspectiva, a solução para esse futuro, que lhes propiciará um negócio próprio, um emprego estável, uma boa qualidade de vida, um futuro digno para eles e para sua família. Assim, os egressos almejam encontrar na vida profissional a plena realização da identidade pessoal e ocupacional.

Frigotto (2007) alerta para o fato de as políticas de formação profissional e de inserção de trabalhadores apagarem a perspectiva do coletivo e realçarem a competição individual. Assim, configura-se "nessas políticas, uma perspectiva estrita de adaptação aos objetivos do mercado e não aos direitos sociais dos trabalhadores e objetivos sociais mais amplos" (FRIGOTTO, 2007, p. 1130).

Conforme sinalizam Frigotto e Ciavatta (2006), existe uma regressão teórica e política, sob a ideologia neoliberal, focando os processos formativos dentro da ideia do cidadão produtivo subordinado à lógica mercantil. Tal afirmação caracteriza-se pelo desejo por um trabalhador flexível, que possua "as competências que se enquadram na lógica do cidadão produtivo, prontamente adaptável e que produz, em tempo mínimo, qualidade máxima e cuja mercadoria ou serviço se realizem no mercado imediatamente" (FRIGOTTO; CIAVATTA, 2006, p. 523).

Os dados analisados na pesquisa também corroboram as observações de Frigotto (2007). Elas estão de acordo com uma lógica unidimensional mercantil e se fundamentam na ideia de que é o indivíduo o responsável por seu sucesso ou insucesso. Porém, encontramos na história do Brasil uma sociedade profundamente estruturada nas raízes da escravidão, em que as oportunidades de trabalhos não avançaram com a mesma proporção dos níveis de educação formal. O desafio é implementar políticas públicas que superem a dualidade entre formação geral e qualificação profissional (FAHEL; RAMBLA; LAZZAROTTI, BRONZO, 2013). 
Após a análise dos resultados, observamos que $48 \%$ dos egressos não continuaram os estudos em nível superior. Identificamos assim a necessidade de incluir a oferta do Curso Técnico em Administração Integrado ao Ensino Médio no Campus Arinos, um curso na área de negócios que oriente aos estudantes a realização de múltiplas escolhas, uma proposta do Ensino Médio Integrado que inclui as disciplinas propedêuticas e proporciona a formação para o ingresso também no Ensino Superior, além da preparação para o mundo do trabalho. Ou seja, integração de conhecimentos gerais e específicos no Ensino Médio, que contemple a formação básica e a profissional de maneira que as pessoas se tornem capazes de compreender a realidade e de produzir a vida (RAMOS, 2007).

Concluímos perguntando qual a percepção em relação à melhoria de qualidade de vida após a conclusão do curso. Segundo as respostas dos egressos, 37\% responderam que melhorou em grande parte, $20 \%$ melhorou um pouco, $18 \%$ melhorou totalmente, $16 \%$ não melhorou e $9 \%$ melhorou a metade.

Portanto, 55\% dos respondentes (melhorou em grande parte e melhorou totalmente) avaliaram que a formação obtida no IFNMG - Campus Arinos se traduziu em benefícios para a sua vida pessoal. Constatamos que 107 (91\%) egressos estão trabalhando no mercado formal, enquanto $11(9 \%)$ se encontram desempregados. Entre os egressos que se encontram empregados, a maior parte trabalha no setor privado (87\%) e $13 \%$ no setor público. A grande parte dos egressos concentra-se no setor privado. Entre os que trabalham, $45 \%$ estão com carteira assinada, $9 \%$ sem carteira assinada, destacando que $7 \%$ se tornaram proprietários de empresas. Quanto à carga horária semanal de trabalho, a maior parte dos egressos (55\%) trabalha no regime de 40 a 44h. Outra parcela está com carga horária acima de $44 \mathrm{~h}$ (13\%), algo que pode gerar descontentamento e, consequente, diminuição da qualidade de vida,

Em relação aos respondentes, observamos que a maioria possui renda mensal na faixa salarial de 1 salário e acima de 1 a 2 salários mínimos (79\%), ou seja, um nível de renda baixo (podendo ser considerado de sobrevivência). Nas faixas de mais de 2 a 3 salários e 3 a 4 salários, respectivamente, $7 \%$ e $5 \%$, concentra-se a segunda maior parcela dos egressos (12\%), parcela em que o egresso se aproxima do nível de renda equivalente ao do salário mínimo necessário calculado pelo Departamento Intersindical de Estatística e Estudos Socioeconômicos (DIESSE), o equivalente a R\$3,92 mil em janeiro de 2019.

Tomando-se a parcela de inseridos no mundo do trabalho, foram cruzadas variáveis que associam a melhoria da qualidade de vida, em virtude da formação obtida no curso, com o nível de satisfação atual, em relação ao nível de satisfação atual em relação ao exercício da atividade profissional. Nesse contexto, cruzando as duas variáveis, podemos concluir que, segundo os egressos, 55\% dos que melhoraram o nível de qualidade de vida após a conclusão do curso estão entre os $65 \%$ dos egressos satisfeitos com a sua atividade profissional na atualidade. Qualidade de vida, neste sentido, pode ser definida como a soma das condições econômicas, ambientais, científico-culturais e políticas coletivamente construídas e postas à disposição dos indivíduos para que estes possam realizar suas potencialidades (HERCULANO, PORTO, FREITAS, 2000).

Por outro lado, conforme os dados da pesquisa, muitos egressos, mesmo concluindo a formação proposta pela instituição, não encontram oportunidades de trabalho na área de formação. Notamos uma parcela de respostas que demonstra insatisfação (18\%) e indiferença $(16 \%)$ em relação a sua atividade profissional atualmente e, 
consequentemente, respostas que a qualidade de vida melhorou pouco (20\%) e não melhorou (16\%).

Em face da escassez relativa de oferta de trabalho na região, em especial na cidade de Arinos, é necessário aprofundar os estudos para os motivos da migração dos jovens da região para as capitais. Como se verifica, a percepção dos próprios egressos denota a existência de carências estruturais, algo que tem dificultado a inserção no mundo do trabalho. Isto sugere que o pressuposto da qualificação profissional como pré-requisito para inserção laboral (quase que imediata) precisa ser revisto, a fim de que haja convergência entre a política de educação e de outras políticas de investimento produtivo.

Conforme os dados da pesquisa, realmente não se pode afirmar que existam estímulos suficientes à permanência de profissionais na Região do Vale do Urucuia, pelas próprias condições estruturais da região. Todavia, alguns buscam superar as dificuldades de maneira proativa, como um egresso destaca: "Então, eu vejo esta questão de trabalhar por conta própria". A egressa "Line" relatou na entrevista que foi a partir do curso Técnico em Administração "que firmei mais a ideia de montar o Ateliê, e aprendi que era possível colocar a minha ideia em prática".

A educação profissional a serviço das transformações sociais deve ser o objetivo de todos os profissionais envolvidos neste processo de formação, sendo assim, na análise dos dados restou clara a necessidade de revisão no currículo do curso com a inclusão de mais disciplinas práticas, e integração com a realidade regional, que garantam ao aluno as condições de aplicabilidade dos conhecimentos obtidos durante o curso, aliados à teoria e à prática.

\section{CONSIDERAÇÕES FINAIS}

No decorrer deste processo de investigação, pudemos perceber que, nossa inquietação acerca do tema proposto é também a inquietação de muitos autores pelo movimento do pensamento através do método materialista histórico-dialético, cuja realidade do mundo do trabalho atualmente apresenta grandes desafios para as instituições de ensino profissional e tecnológico. É importante ressaltar que estes desafios são o conjunto de realidades que compõem o nosso país, desde sua colonização, pois tratar uma dualidade na educação que nasceu com a história do Brasil não é uma tarefa fácil. Muitos jovens não concluíram os cursos ou não continuam os estudos devido à necessidade de provimento do próprio sustento ou o sustento das suas famílias, principalmente os que se encontram em situação de pobreza.

Os principais resultados da pesquisa apontam que o Curso Técnico em Administração tem resultados positivos para a inserção no mercado de trabalho, mas as análises relativas aos salários dos trabalhadores apontam que há diferenças entre os salários da categoria ao nível nacional. Portanto, mesmo a inserção no mundo produtivo, de forma qualificada, não produz efeitos positivos em curto prazo sobre o salário.

Os egressos estão satisfeitos com o curso e com o IFNMG - Campus Arinos, contudo, de forma geral, entendem a necessidade urgente da inclusão de disciplinas práticas, da reformulação da matriz curricular do curso, reconhecem lacunas no conhecimento que construíram. Teoria e prática devem ser integradas, segundo os entrevistados, a fim de garantir a formação do ser humano por inteiro e do profissional administrador. 
As sugestões após a presente pesquisa se dão no sentido de revisão da matriz curricular, na capacitação docente para que se pense em novas práticas pedagógicas, sempre levando em consideração o mundo do trabalho e suas transformações. Os egressos sugeriram ainda a criação de projetos de extensão que garantam a aplicabilidade das teorias e uma reflexão sobre o perfil do administrador, assegurando a inserção profissional do Técnico em Administração nas mais diversas formas: gestores no serviço público e privado, identificação de novas oportunidades de negócio próprio, gestores na agricultura familiar.

Reforçamos a importância de constantes revisões curriculares, para que as transformações do mundo não fiquem de fora das transformações dos sujeitos, em suas vidas e como profissionais, sendo a instituição de ensino; fundamental para esta evolução. Torna-se relevante repensar a educação profissional, atentos aos aspectos que incidem na inserção de egressos, tendo em vista a responsabilidade social dos Institutos Federais de Educação. A necessidade de mudança é apontada pelos egressos e convém retomar as sugestões por eles expostas: incluir aulas práticas; buscar parcerias com as instituições públicas e privadas da região para encaminhar os alunos para os estágios com possibilidade de futura contratação; criar estratégias para diminuir a retenção e evasão no curso.

Nesse sentido, propomos, ao fim deste estudo, a oferta do Curso Técnico em Administração Integrado ao Ensino Médio no IFNMG - Campus Arinos, com o currículo que integra a formação e o mundo do trabalho. Os núcleos de formação seriam divididos em: núcleo comum, as Ciências Humanas, Linguagens, Ciências Exatas e Ciências da Natureza; núcleo técnico, composto pelas disciplinas que tratam dos conhecimentos, competências e habilidades fundamentais para os diversos desafios colocados pelo mundo do trabalho, bem como dos instrumentos pertinentes ao eixo tecnológico do curso; núcleo politécnico, espaço de organização curricular de interseção entre os conhecimentos, competências e habilidades de componentes curriculares, do núcleo comum ou do núcleo técnico, que podem integrar-se através de projetos.

Esta pesquisa apresenta, portanto, dados interessantes para o cenário de políticas públicas de qualificação profissional, direcionadas às regiões com baixo índice de desenvolvimento, demonstrando que ações efetivas para a inserção no mundo do trabalho devem ser fomentadas e ampliadas na região. Pelos resultados apresentados, a opção por ofertar cursos técnicos de nível médio cria melhores oportunidades para o primeiro emprego em condições favoráveis de trabalho. Essa inclusão produtiva é fator de suma importância para a própria integração das camadas menos favorecidas da região à sociedade.

\section{REFERÊNCIAS}

BRASIL. Lei no 4.024, de 20 de dezembro de 1961. Fixa as Diretrizes e Bases da Educação Nacional. Diário Oficial da União, Brasília, DF, 27 dez. 1961. Disponível em: http://www.planalto.gov.br/ccivil_03/leis/L4024.html. Acesso em: 19 abril 2019.

BRASIL. Lei $\mathrm{n}$ ⒌692/1971, de 11 de agosto de 1971. Fixa as Diretrizes e Bases para o ensino de $1^{\circ}$ e $2^{\circ}$ graus, e dá outras providências. Diário Oficial da União, Brasília, DF, ago. 1971. Disponível em: https://www2.camara.leg.br/legin/fed/lei/1970-1979/lei-5692-11-agosto-1971. Acesso em: 19 abril 2019.

BRASIL. Ministério da Educação. Plano de desenvolvimento institucional (PDI). Instituto Federal do Norte de Minas Gerais. Junho de 2013. 
BRASIL. Ministério da Educação. Regulamento da Política de Assistência Estudantil do IFNMG. Instituto Federal do Norte de Minas Gerais. Dezembro de 2017.

FAHEL, Murilo; RAMBLA, Xavier; LAZZAROTTI, Bruno; BRONZO, Carla. (Org.). Desigualdades educacionais \& pobreza. Belo Horizonte: PUC Minas, 2013.

FRIGOTTO, Gaudêncio. A relação da educação profissional e tecnológica com a universalização da educação básica. Educ. Soc., Campinas, vol. 28, n. 100 - Especial, p. 1129-1152, out. 2007. Disponível em: http://www.scielo.br/pdt/es/v28n100/a2328100. Pdf. Acesso em: 10 de jul. 2019.

FRIGOTTO, Gaudêncio; CIAVATTA, Maria. (Org.). A formação do cidadão produtivo: a cultura do mercado no ensino médio técnico. Brasília, DF: INEP, 2006.

FRIGOTTO, Gaudêncio; CIAVATTA, Maria; RAMOS, Marise. Concepções e mudanças no mundo do trabalho e o ensino médio. In: Ensino médio integrado: concepções e contradições. 1 ed. São Paulo: Cortez, 2005.

HERCULANO, Selene; PORTO, Marcelo Firpo de Souza; FREIRAS, Carlos Machado de. Qualidade de vida e Riscos ambientais. Niterói: EdUFF, 2000.

IFNMG, Projeto Pedagógico do Curso Técnico em Administração concomitante/subsequente. Arinos, 2017.

KUENZER, Acacia Zeneida. Ensino médio e profissional: as políticas do Estado neoliberal. São Paulo: Cortez, 1997.

MALHEIROS, Bruno Taranto. Metodologia da Pesquisa em Educação. 1 ed. Rio de Janeiro: LTC, 2011.

MEC. Secretaria de Educação Média e Tecnológica. Políticas Públicas para a Educação Profissional e Tecnológica. Brasília: Ministério da Educação Ciências e Tecnologia, 2004. Disponível em: http://portal.mec.gov.br/setec/arquivos/pdf/pp.pdf. Acesso em: 18 jan. 2018.

MOURA, Dante Henrique. Educação Básica e Educação Profissional e Tecnológica: Dualidade histórica e perspectivas de integração. Holos, v. 2, 2007.

NEVES, Lúcia Maria Wanderley (org.). Educação e política no limiar do século XXI. Campinas: Autores Associados, 2000, p. 79-102.

RAMOS, Marise. Concepção do ensino médio integrado. Seminário sobre ensino médio, realizado pela Superintendência de Ensino Médio da Secretaria de Educação do Estado do Rio Grande do Norte. 2007. Disponível em: http://proferlaotrabalhosalunos.pbworks.com/w/file/fetch/87991939/curriculo_integrado.pdf. Acesso em: 10 jul. 2019.

XAVIER, Maria Elisabete Sampaio Prado. Capitalismo e escola no Brasil. Campinas, SP: Papirus, 1990.

Data da submissão: 07/08/2020

Data da aprovação: 12/12/2020 